\title{
Yanık ünitesi olan tek merkezde geriatrik hastaların yönetimi ve mortaliteyi etkileyen faktörler
}

\author{
Management of geriatric burn patients in one center with burn unit and the factors \\ correlated with mortality
}

\author{
Erkan $\operatorname{Yavuz}^{1}$ (D) Onur Olgaç Karagülle ${ }^{1}$ (D) \\ 1 İstanbul Bağcılar Eğitim ve Araştırma Hastanesi, Genel Cerrahi Kliniği
}

\section{Öz.}

Amaç: Bu non-invaziv retrospektif klinik çalışmada, yanık merkezimizde takip ve tedavi ettiğimiz geriatrik yaş gurubu hastalarda mortaliteyi etkileyen faktörleri incelemeyi amaçladık.

Materyal ve Metot: Yanık merkezinde 2016 Ocak ile 2019 Ocak tarihleri arasında yataklı servis ve yanık yoğun bakım servisinde takip edilen geriatrik yaş grubunda (65 yaş ve üzeri) 86 hasta dahil edilmiş̧tir. Hasta dosyaları yaş, cinsiyet, yanık etiyolojisi, yanık yüzdesi [total vücut yüzey alanı (TVYA)], yanık bölgesi, serviste/yoğun bakımda yatış süresi, eşlik eden (komorbid) hastalıklar, cerrahi işlemler (Debritman/eskaratomi), yanık derinliği, ASA skoru, greft ve entübasyon yapılma durumları ve mortalite oranı retrospektif incelendi. Hastalar serviste takip edilen (hiç yoğun bakım intiyacı olmayanlar) ve yoğun bakım da takip edilen (öncelikle yoğun bakıma kabul edilen -taburculuk öncesi servise alınanlar) hastalar olmak üzere iki gruba ayrilarak demografik ve klinik veriler gruplar arasında karşılaştıııldı.

Bulgular: Charlson komorbidite indeksi (CCI) skorları, serviste yatan hastaların çoğunda $(\% 58,3)$ orta şiddette seyrederken yoğun bakımda yatan hastaların çoğunda ise $(\% 76,3)$ şiddetli derecede idi. Serviste yatanların çoğunda $(\% 54,2)$ sıvı yanığı, yoğun bakımda yatanların yarııında (\%50) alev yanığı görüldü. Tüm hastaların TVYA ortalamaları $\% 16,07$ olup, $\% 20$ ve üzeri TVYA olan hastaların sayısı yoğun bakım grubunda servis grubuna kıyasla anlamlı düzeyde fazla idi $(P<0,0001)$. Anatomik yanık bölgelerine göre servis hastalarııı çoğunda $(\% 31,25)$ ayakta yanık görülürken yoğun bakım hastalarının çoğunda $(\% 60,53)$ uyluk ve bacak yanıkları görüldü. İki grup arasında baş/yüz, üst ve alt ekstiremiteler ve gövde yanıklarının insidansları açısından anlamlı farklara rastlandı $(P<0,05)$. Yanık derinliği açısından hasta grupları karşılaşııııldığında 2. Derecede yanıklar her iki grupta da en sık görülen yanıklardı. Tüm hastaların mortalite oranı $\% 17,44$ ve yoğun bakım hastalarında ise \%39,47 idi. Komorbid hastalıklar, yanık alanın büyüklüğü ve derinliği, ASA skoru, cerrahi müdahaleler ve entübasyon uygulaması ile mortalite arasında pozitif korelasyonlar saptandı. Alev ile oluşan veya elde, gövdede, alt ekstremitede ve ayaktaki yanıklarda artışla birlikte mortalitenin artışı izlendi.

Sonuç: Yanık hastaları arasında mortalitesi en yüksek oranlarda bulunan geriatrik yaş grubunda gerek eșlik eden hastalıklar gerekse yaşlanmanın vücudun tüm sistemleri üzerine olan olumsuz etkisi nedeniyle hastaların tedavi ve takibinde multidisipliner yaklaşım ile mortalite ve morbiditenin azalabileceğini umuyoruz.

Anahtar Kelimeler: Yanık, Geriatri, Mortalite, Morbidite, Komorbidite

Abstract

Background: This non-invasive retrospective clinical study aims to investigate the factors correlated with mortality in geriatric patients followed up and treated in our burn center.

Methods: Eighty six patients in geriatric age (>65 years old) followed up in burn unit or ICU of burn center between 2016 January and 2019 January were selected. The data of patients including age, gender, burn etiology, burn percentage [Total body surface area (TBSA)], burn location, duration of hospitalization, comorbidities, surgical operations (debridement/escharotomy), burn depth, ASA score, application of graft or intubation and mortality rates were evaluated retrospectively. The patients were divided into two groups according to their hospitalization unit; the burn unit (BU) group and ICU group and their demographic and clinical findings were compared.

Results: Considering Charlson comorbidity index (CCI), most of the patients (58.3\%) in BU group had moderate comorbidities while most of ICU group (76.3\%) had severe scores. Most of the patients in BU group (54.2\%) had burns caused by liquids while half of the patients in ICU had flame burns. Overall TBSA in all patients was 16.07\%, and the number of TBSA higher than $20 \%$ among ICU patients was higher than $\mathrm{BU}$ group $(\mathrm{P}<0.0001)$. Considering the anatomic region, the most of patients in BU group had burns on feet $(31.25 \%)$ while most of ICU patients $(60.53 \%)$ had burns on lower extremities. There were significant differences among groups in terms of the incidence of burned regions on head/face, upper and lower extremities and trunk $(P<0.05)$. The most observed burn depth in both groups was second-degree burns. The mortality rate among all patients was $17.44 \%$ and among ICU patients was $39.47 \%$. However, the mortality rate was positively correlated with $\mathrm{CCI}$, TBSA, burn depth, ASA scores, number of surgical operations and intubation. The increasing incidence of flame burns, burns on hands, trunk, lower extremities and feet were also correlated with the increase in mortality rate.

Conclusions: The mortality and morbidity rates may be reduced by a multidisciplinary approach to treat and follow-up the geriatric age group who has the highest mortality rates among burn patients due to their high rate of comorbidities and adverse effects of aging.

Keywords: Burn, geriatrics, Mortality, Morbidity, Comorbidity

\section{Sorumlu Yazar I Corresponding Author}

Dr. Erkan Yavuz

İstanbul Bağcılar Eğitim ve Araştırma Hastanesi, Genel Cerrahi Kliniği 34200 Bağcılar / İstanbul, Türkiye

Tel: +90 5324986870

E-mail: 81drerkanyavuz@gmail.com

Geliş tarihi / Received: 05/05/2019

Kabul tarihi / Accepted: 01/08/2019

DOI: $10.35440 /$ hutfd. 560672 


\section{Giriş}

Yaşlılık fizyolojisi nedeniyle reflekslerde yavaşlama ve görme fonksiyonlarında bozulma travma ihtimalini arttırmakta ve geriatrik yaşlarda travmaların \% 8'ini yanıklar oluşturmaktadır. Yaşlı hastalarda yanığa bağlı morbidite ve mortalite oranları daha yüksek izlenmektedir (1).

Yaşlı hastalarda yüksek mortalitenin ana etkenleri arasında hastalarda bulunan kronik hastalıklar, enfeksiyona yatkınlık, kardiopulmoner rezervde azalma, protein enerji malnutrisyonu ve derinin özellikleri yer almaktadır (2). Yanıklardan sağ kalım oranı etkilenen total vücut yüzey alanı ile ilişkili olmasına rağmen yaşlılarda bu oran daha düşüktür. Yaşlılarda total vücut yüzey alanının \%40'ından fazlasını kaplayan yanıklar genellikle çok kötü prognoz gösterir. Yanıklara bağılı artan mortalite oranının sebepleri ise var olan hastalıklar, yanık yeri sepsisi ve çoklu sistem yetmezlikleridir (3). Benzer yanık oranlarına sahip genç hastalara kıyasla yaşlılarda morbidite ve mortalite oranları yüksektir (4). Bu sebeple özellikle geriatrik yaş grubu yanık hastalarında uygun ekipman ve bilgiye sahip, multidisipliner çaıışma şartları olan merkezlerde tedavinin sürdürülmesi önemlidir.

Bu çalışmada Sağlık Bilimleri Üniversitesi Bağcılar Eğitim Araştırma Hastanesi yerleşkesine bağlı yanık merkezimizde yataklı servis ve yanık yoğun bakımımızda yatarak takip ve tedavi ettiğimiz geriatrik yaş gurubu hastalarında mortaliteyi etkileyen faktörleri incelemeyi ve serviste takip edilenler ile yoğun bakım servisinde takip edilen hastaları bu faktörlere göre karşılaştırmayı amaçladık.

\section{Materyal ve Metot}

Bu çalışma non-invaziv retrospektif klinik bir çalışmadır. Çalışmamıza hastanemiz yanık merkezinde 2016 Ocak ile 2019 Ocak tarihleri arasında yataklı servis ve yanık yoğun bakım servisinde takip edilen geriatrik yaş grubunda ( 65 yaş ve üzeri) 86 hasta dahil edilmiştir. Hasta dosyaları yaş, cinsiyet, yanık etiyolojisi, yanık yüzdesi (total vücut yüzey alanı), yanık bölgesi, serviste/yoğun bakımda yatış süresi, eşlik eden (komorbid) hastalıklar, ccerrahi işlemler (Debritman/eskaratomi), yanık derinliği, ASA skoru, greft ve entübasyon yapılma durumları ve mortalite oranı retrospektif incelenerek geriatrik yaş grubu hastalarda mortaliteye etki eden faktörler incelendi. Hastalar serviste takip edilen (hiç yoğun bakım intiyacı olmayanlar) ve yoğun bakım da takip edilen (öncelikle yoğun bakıma kabul edilen -taburculuk öncesi servise alınanlar) hastalar olmak üzere iki gruba ayrılarak demografik ve klinik veriler gruplar arasında karşılaştırıldı.

Komorbid hastalıkların şiddeti Charlson komorbidite indeksine (CCl) göre skorlanmıştır. CCl skorları Charlson ve ark. tarafından belirlenen skorlama sistemine göre hesaplanmıştır (5). Hastalar bu indekse göre üç gruba ayrımıştır: hafif komorbidite $\mathrm{CCl}$ skorları 1-2; orta şiddette komorbidite $\mathrm{CCl}$ skorları 3-4 ve şiddetli komorbidite $\mathrm{CCl}$ skoru 5 ve 5’ten büyük. CCl'da kardiyo-serebrovasküler hastalık komorbiditeleri, kardiyak aritmi, periferik vasküler hastalıklar, sereberal vaskülopati, iskemik kalp hastalığı veya kronik kalp yetmezliği hikayesi olarak tanımlanmıştır (6).

Çalışma için girişimsel olmayan klinik araştırmalar yerel etik kurulundan izin alındı (Sayı: 2017/588, Tarih: 13.06.2017).

\section{İstatistiksel Analiz}

İstatistiksel analizler GraphPad Instat ver. 3.06 (GraphPad Inc, $C A, A B D$ ) bilgisayar programı ile yapılmışıı. Grup içi tüm verilerin normal dağılıma uygunluğu KolmogorovSmirnov testi ile test edilmiştir. Parametrik verilerin ortalamaları one way ANOVA testi ile, gruplar arası farklılıklar ise Tukey-Kramer çoklu karşılaştırma testi ile karşılaştırımıştır. Non-parametrik veriler ise non-parametrik ANOVA testi ile ve gruplar arası farklııklar Kruskal Wallis testi (with post test) ile karşılaştırımıştır. Kategorik değişkenler arasındaki ilişkiler ise Fisher Exact Ki-kare, Yates Kikare analizleri ile değerlendirildi. Dağılım normal olmadığında iki sürekli değişken arasındaki ilişkinin belirlenmesinde Spearman Rho Korelasyon Katsayısı kullanılmış, ikiden fazla çoklu korelasyonlar multipl regresyon analizi ile yapılmıştır. $P<0,05$ değeri farklı gruplar için istatistiksel olarak anlamlı kabul edilmiştir.

\section{Bulgular}

Çalışmamıza yataklı servis ve yoğun bakım da takip edilen 65 yaş ve üzeri toplam 86 hasta dahil olup, 41'i erkek $(\% 47,67), 45$ i kadındı $(\% 52,32)$. Serviste yatan hastaların yaş ortalaması $73,62 \pm 6,03$ ve yoğun bakımda yatan hastaların yaş ortalaması $76,47 \pm 8,69$ olup aralarında istatistiksel açıdan fark yoktur (Tablo 1). Erkek ve kadın hastaların oranları açısından da gruplar arasında fark yoktu. Yanıkların \%86,04'ü ev kazalarından, \%12,79'u ise kriminal olaylardan kaynaklanmaktaydı. Mevsimsel olarak incelendiğinde 10 vaka $(\% 11,62)$ ilkbaharda, 48 vaka $(\% 55,81)$ kış aylarında, 12 vaka $(\% 13,95)$ sonbaharda ve 16 vaka $(\%$ 18,06) yaz aylarında izlendi. CCl skorları incelendiğinde serviste yatan hastaların çoğunda $(\% 58,3)$ komorbid hastalıkları daha çok orta şiddette seyrederken yoğun bakımda yatan hastaların çoğunda ise $(\% 76,3)$ şiddetli derecede idi ve iki grup arasındaki fark anlamlıydı ( $P=0,0027)$. Vakalar etiyolojik olarak incelendiğinde serviste yatan hastaların çoğunda $(\% 54,2)$ sıvı yanığı, üçer hastada kimyasal $(\% 6,3)$ ve temas yanıkları $(\% 6,3)$ ve bir hastada $(\% 2,1)$ elektrik yanığı görüldü. Yoğun bakımda yatan hastaların yarısında (\%50) alev yanığı, 16 'sında $(\% 42,1)$ sıcak sıvı, üçünde kimyasal yanık $(\% 7,9)$ görüldü fakat hiçbirinde temas veya elektriğe bağlı yanık görülmedi. Yanık etiyolojileri açısından gruplar arasında anlamlı fark yoktu (Tablo 1). İlk yatışı yataklı servis olan iki hastamız $(\% 4,16)$ takipleri sırasında yoğun bakım servisine alındı. Bu hastaların birinde aspirasyon pnomonisi, diğerinde ise ekstiremite ampütasyonu gerekliği ve solunumsal sıkıntı nedeniyle yoğun 
bakım endikasyonu oluştu. El bölgesinde yanığı olan bir hasta servis yatışının ilk gününde tedaviyi reddederek ayrılırken, 23 hasta yoğun bakımdaki tedavileri sonlandırılarak serviste takipleri yapıldı.

Tablo 1. Serviste takip edilen ve yoğun bakımda takip edilen yanık hastalarının demografik ve yanık özellikleri

\begin{tabular}{|c|c|c|c|}
\hline & Servis (n: 48) & $\begin{array}{l}\text { Yoğun Bakım } \\
\text { (n: 38) }\end{array}$ & $P$ değeri \\
\hline Yaş (Ort $\pm S S$ ) & $73,62 \pm 6,03$ & $76,47 \pm 8,69$ & 0,172 \\
\hline \multicolumn{4}{|l|}{ Cinsiyet } \\
\hline Erkek (\%) & $24(50)$ & $17(44,7)$ & \multirow[t]{2}{*}{0,788} \\
\hline Kadın (\%) & $24(50)$ & $21(55,3)$ & \\
\hline \multicolumn{4}{|l|}{$\mathrm{CCl}$} \\
\hline Orta (\%) & $28(\% 58,3)$ & $9(\% 23,7)$ & \multirow[t]{3}{*}{$0,0027^{*}$} \\
\hline Şiddetli (\%) & $20(\% 41,7)$ & $29(\% 76,3)$ & \\
\hline \multicolumn{3}{|c|}{ Yanık Etiyolojisi (\%) } & \\
\hline Sivi & $26(\% 54,2)$ & $16(\% 42,1)$ & 0,371 \\
\hline Alev & $15(\% 31,3)$ & $19(\% 50)$ & 0,123 \\
\hline Kimyasal & $3(\% 6,3)$ & $3(\% 7,9)$ & 0,766 \\
\hline Temas & $3(\% 6,3)$ & $0(\% 0)$ & 0,329 \\
\hline Elektrik & $1(\% 2,1)$ & $0(\% 0)$ & 0,371 \\
\hline \multicolumn{4}{|l|}{ TVYA (\%) } \\
\hline$\% 1-10$ & $36(\% 75)$ & $12(\% 31,58)$ & $0,001^{*}$ \\
\hline$\% 10-20$ & $9(\% 18,75)$ & $7(\% 18,42)$ & 0,967 \\
\hline$\% 20$ ve üzeri & $3(\% 6,25)$ & $19(\% 50)$ & $<0,0001^{*}$ \\
\hline \multicolumn{4}{|c|}{ Anatomik yanık bölgeleri (\%) } \\
\hline Baş/yüz & $10(\% 2,08)$ & $18(\% 47,37)$ & $0,018^{*}$ \\
\hline El & $14(\% 29,2)$ & $16(\% 42,11)$ & 0,307 \\
\hline Üst ekstiremite & $13(\% 27,08)$ & $21(\% 55,26)$ & $0,015^{*}$ \\
\hline Gövde & $13(\% 27,08)$ & $22(\% 57,89)$ & $0,0076^{*}$ \\
\hline Uyluk -bacak & $13(\% 27,08)$ & $23(\% 60,53)$ & $0,0037^{*}$ \\
\hline Ayak & $15(\% 31,25)$ & $12(\% 31,58)$ & 0,974 \\
\hline \multicolumn{4}{|c|}{ Yanık Derinliği (\%) } \\
\hline 2. derece & $40(\% 83,3)$ & $22(\% 57,9)$ & \multirow{2}{*}{$0,018^{*}$} \\
\hline 3. derece & $8(\% 16,7)$ & $16(\% 42,11)$ & \\
\hline
\end{tabular}

Inhalasyon yanık hastaları dışlandığında yataklı servis ve yoğun bakım servisine yatan hastaların total vücut yanık alanı (TVYA) ortalamaları \%16,07 olup, ilk yatışı yataklı servise olan hastalarda bu ortalama $\% 8,32$, ilk yatışı yoğun bakım servisi olan hastalarda ise $\% 25,86$ idi. Serviste yatan hastaların \%1 ila \%10 arasında TVYA görülen hasta sayısı $36(\% 75)$ iken yoğun bakımdaki hastalarda bu sayı $12(\% 31,58)$ idi (Tablo 1). Gruplar arasındaki fark istatistiksel olarak anlamlıydı $(P=0,001)$. \%20 ve üzeri TVYA olan hastaların sayısı serviste yatanlar arasında üç $(\% 6,25)$ iken yoğun bakımda yatanlar arasında $19(\% 50)$ idi. Bu artış da istatistiksel olarak anlamlı bulundu $(P<0,0001)$. Yoğun bakım da yatışı olan hastalar içinde TVYA en fazla olan hastamız $\% 90$, servis hastalarında ise en fazla \%36 idi (Tablo 1).

Serviste takip edilen hastaların anatomik yanık bölgelerine göre dağılımı incelendiğinde vakaların çoğunda $(\% 31,25)$ ayakta yanık görülürken en az $(\% 2,08)$ başta veya yüzde yanık görüldü. Yoğun bakımda yatan hastaların çoğunda $(\% 60,53)$ ise yanıklar uyluk ve bacak en az ise $(\% 31,58)$ ayakta görüldü. İki grup arasında baş/yüz, üst ekstiremite, gövde ve alt ekstiremite yanıklarının insidansları açısından anlamlı farklara rastlandı (sırasıyla $P=0,018, P=0,015$, $\mathrm{P}=0,0076$ ve $\mathrm{P}=0,0037$ ).

Yanık derinliği açısından hasta grupları karşılaştırıldığında 2. Derecede yanıklar her iki grupta da en sık görülen yanıklardı (Tablo 1). Serviste yatan hastaların \%83,3'ünde 2.
Derecede yanık görülmüş iken yoğun bakım hastalarının $\% 57,9$ 'unda bu derinlikte yanıklar görüldü ve iki grup arasındaki fark anlamlı idi ( $P=0,018)$.

Hastaların serviste yatış süresi gün ortalaması ile yoğun bakımda yatış süresi ortalaması arasında fark yoktu (Tablo 2). ASA skorları açısından serviste yatan hastaların çoğunun $(\% 79,2)$ skoru III iken yoğun bakımda yatan hastaların çoğunun $(\% 52,6)$ ise IV idi ve skorlar açısından iki grup arasındaki farklar anlamlı bulundu (ASA III için $\mathrm{P}=0,0002$, ASA IV için $\mathrm{P}<0,0001$ ).

Hastalara yapılan cerrahi müdahalelerden debritman veya eskaratomi sayısı 0 ila 10 arasında olan hastaların sayısı serviste yatanlarda $42(\% 87,5)$ iken yoğun bakımda yatanlarda $24(\% 63,16)$ idi (Tablo 2). 10'dan fazla sayıda cerrahi müdahale yapılan hasta sayısı yoğun bakımda yatan hastalarda anlamlı derecede fazla idi $(P=0,0165)$. Iki grup arasında deri greft uygulaması yapılan hasta sayıları açısından anlamlı bir farka rastlanmadı.

Yoğun bakım servisinde yatan hastaların \%34,2'si ( $N=13)$ entube olarak, $\% 5,26$ 'sı $(n=2)$ trakeostomili takibi yapilırken, üç hastada takipler sırasında ekstiremite ampütasyonu yapıldı. Bir hastada total mezenter iskemi nedenli total kolektomi yapıldı.

Hastaların mortalite oranı tüm hastalar arasında \%17,44 idi ve bu hastaların hepsi yoğun bakımda yatan hastalardandı (Tablo 2). Illk yatışı servise olan hastalarda takip sırasında mortalite oranı $\% 2,08$ olup, aspirasyon pnömonisi nedenliydi. Yoğun bakım servisinde ise mortalite oranı \%39,47 idi. Ünitemizde yataklı servis ve yoğun bakımda mortal seyreden hastalarda en sık ana neden kardiyovaskuler yetmezlik olup, en sık komorbid hastalık hipertansiyon idi. Mortalitenin altında yatan sebeplerini araştırdığımızda cinsiyet ile mortalite arasında bir ilişki saptanmadı (Tablo 3). Fakat komorbid hastalıklar açısından, yanık alanın büyüklüğü ve derinliği açısından mortalite ile pozitif bir korelasyon saptandı $(P<0,0001)$. Yanık etiyolojilerinden daha çok alev ile yanıklarda mortalitenin artışı izlendi $(P=0,0009)$. Anatomik yanık bölgeleri arasında ise elde, gövdede, uyluk/bacak da ve ayaktaki yanıklarda artışla mortalite arasında pozitif bir korelasyon yakalandı (sırasıyla $\mathrm{P}=0,0208$, $\mathrm{P}=0,0011, \mathrm{P}<0,0001$ ve $\mathrm{P}=0,0015$ ).

Mortalitenin sebepleri ile peroperatif ve postoperatif verilerin çoklu regresyon ve korelasyon analizlerine göre yatış süreleri, ASA skoru, cerrahi müdahaleler ve entübasyon uygulaması ile mortalite arasında pozitif korelasyonlar izlendi (sırasiyla $P=0,0028, \quad P<0,0001, P=0,0002$ ve $P<0,0001)$. Deri greft uygulaması ile mortalite arasında bir korelasyona rastlanmadı (Tablo 4).

\section{Tartışma}

Yanıkla ilişkili hastaneye yatışların yaklaşık \%7-8'ini yüksek risk grubundaki 60 yaş üzeri hastaların oluşturduğu gösterilmiştir $(1,7,8)$. Ancak geriatrik hastaların mortalite 
oranlarını yanık parametreleri, klinik parametreleri ve postoperatif verileri ile ilişkilendiren araştırma ülkemizde henüz yapılmamışıır. Bu nedenle çalışmamızda yanık servisimizde yatan hastalar ile yoğun bakım biriminde yatan hastaların preoperatif, peroperatif ve postoperatif bulgularını retrospektif karşılaştırmanın yanısıra mortaliteye olan katkılarını da analiz etmeyi amaçladık. Sonuçta mortaliteye yol açan faktörleri komorbid hastalıklar, yanık alanın büyüklüğü, derinliği, bazı yanık etiyolojileri, anatomik yanık bölgeleri, hastanede yatış süreleri, ASA skoru, cerrahi müdahaleler ve entübasyon uygulaması olarak belirledik.

Tablo 2. Serviste takip edilen ve yoğun bakımda takip edilen yanık hastalarının pre-peroperatif ve postoperatif klinik özellikleri

\begin{tabular}{|c|c|c|c|}
\hline & $\begin{array}{l}\text { Servis (n: } \\
48)\end{array}$ & $\begin{array}{l}\text { Yoğun Bakım } \\
\text { (n: } 38)\end{array}$ & $P$ değeri \\
\hline Yatış süresi gün (Ort $\pm S S$ ) & $\begin{array}{l}19,75 \quad \pm \\
19,82\end{array}$ & $19,08 \pm 25,45$ & 0,814 \\
\hline \multicolumn{4}{|l|}{ ASA skoru } \\
\hline$\|$ & $8(\% 16,7)$ & $4(\% 10,5)$ & 0,615 \\
\hline III & $38(\% 79,2)$ & $14(\% 36,8)$ & $0,0002^{*}$ \\
\hline IV & $2(\% 4,2)$ & $20(\% 52,6)$ & $<0,0001^{*}$ \\
\hline \multicolumn{4}{|l|}{ Debritman/eskaratomi (\%) } \\
\hline $0-10$ & $42(\% 87,5)$ & $24(\% 63,16)$ & \\
\hline$>10$ & $6(\% 12,5)$ & $14(\% 36,84)$ & $0,0165^{*}$ \\
\hline Greft (\%) & $4(\% 8,3)$ & $3(\% 7,9)$ & 0,941 \\
\hline Entübasyon (\%) & $0(\% 0)$ & $13(\% 34,2)$ & $<0,0001^{*}$ \\
\hline Mortalite (\%) & $0(\% 0)$ & $15(\% 39,47)$ & $<0,0001^{*}$ \\
\hline
\end{tabular}

Ort \pm SS: Ortalama \pm Standart sapma, CCl: Charlson Komorbidite Indeksi, TVYA: Etkilenen total vücut yüzey alanı, ASA (American Society of Anesthesiologists) ${ }^{*} P<0,05$ anlamlı kabul edildi.

Tablo 3. Geriatrik yanık hastalarında mortalitenin demografik özellikler ve yanık parametreleri ile korelasyonu

\begin{tabular}{llll}
\hline & Spearman $\mathrm{r}$ & $\mathrm{Cl}$ & $\mathrm{P}$ değeri \\
\hline Cinsiyet & $-0,113$ & $-0,323-0,107$ & 0,298 \\
CCI & 0,459 & $0,268-0,615$ & $<0,0001^{*}$ \\
Yanık Etiyolojisi & $\mathrm{t}$ ratio & & \\
SIVI & 0,203 & $-0,210-0,257$ & 0,840 \\
Alev & 3,436 & $0,173-0,651$ & $\mathbf{0 , 0 0 0 9 ^ { * }}$ \\
Kimyasal & 0,844 & $-0,638-0,259$ & 0,401 \\
Temas & 0,844 & $-0,638-0,259$ & 0,401 \\
Elektrik & 0,968 & $-0,581-0,201$ & 0,336 \\
TVYA & 0,622 & $0,467-0,740$ & $<0,0001^{*}$ \\
Anatomik yanık bölgeleri & t ratio & & \\
Baş/yüz & 1,281 & $-0,032-0,256$ & 0,204 \\
El & 2,361 & $-0,056-0,256$ & $\mathbf{0 , 0 2 0 8 ^ { * }}$ \\
Üst ekstiremite & 1,551 & $0,025-0,302$ & 0,125 \\
Gövde & 3,385 & $0,090-0,346$ & $\mathbf{0 , 0 0 1 1 ^ { * }}$ \\
Uyluk-bacak & 5,254 & $0,212-0,470$ & $<0,0001^{*}$ \\
Ayak & 3,303 & $0,090-0,364$ & $\mathbf{0 , 0 0 1 5 ^ { * }}$ \\
Yanık Derinliği & 0,444 & $0,248-0.604$ & $<0,0001^{*}$ \\
\hline Cl: Güven aralığı, CCl: Charlson Komorbidite indeksi, TVYA: Etkilenen total vücut yüzey \\
alanı, ${ }^{*} P<0,05$ mortalite ile pozitif bir korelasyon mevcuttur & \\
& \multicolumn{3}{l}{}
\end{tabular}

Tablo 4. Geriatrik yanık hastalarında mortalitenin peroperatif ve postoperatif klinik özellikleri ile korelasyonu

\begin{tabular}{clll}
\hline & $\mathrm{t}$ ratio & $\mathrm{Cl}$ & $\mathrm{P}$ değeri \\
\hline Yatış süresi & 3,086 & $0,002--0,012$ & $\mathbf{0 , 0 0 2 8}^{*}$ \\
\hline ASA skoru & Spearman $\mathrm{r}$ & $\mathrm{Cl}$ & $\mathbf{P}$ değeri \\
\hline Debritman/eskaratomi & 0,575 & $0,408-0,705$ & $<0,0001^{*}$ \\
Greft & 0,390 & $0,188-0,560$ & $\mathbf{0 , 0 0 0 2 ^ { * }}$ \\
Entübasyon & $-0,137$ & $-0,345-0,084$ & 0,209 \\
Cl: Güven aralığı, ${ }^{*} P<0,05$ mortalite ile pozitif bir korelasyon mevcuttur
\end{tabular}

Yanığın prognozunu belirleyen faktörler hastaların yaşı, genel durumu, yanığın etiyolojisi, yanık alanı, derinliği ve lokalizasyonudur. Ülkemizde geriatrik hastalarda yanık alanına göre mortalite genç hastalara göre beklenenden çok daha yüksek orandadır $(1,2)$. Bu oranlara komorbid hastalıkların varlığı da etki etmekte ve artan mortaliteden büyük oranda sorumlu tutulmaktadır (9). Düzgün ve ark. 60 yaş ve üstü 54 hastaya ait kayıtları değerlendirdikleri retrospektif bir çalışmada hastaların \%45'inin tıbbi hastalıklara sahip olduklarını ve bunların \%35'inin mortal olarak seyrettiğini kaydetmiştir (1). Çalışmamızda serviste yatan hastaların çoğunda komorbid hastalıklar daha çok orta şiddette seyrederken yoğun bakımda yatan hastaların çoğunda ise şiddetli derecede görülmüştür. Ayrıca mortalite ile $\mathrm{CCl}$ indeksi arasında saptanan pozitif korelasyon komorbid hastalıkların şiddeti ile mortalitenin ilişkili olabileceğini göstermiştir. Yanık travmalarından kaynaklanan devamlı stres, özellikle önceden tıbbi problemlere sahip hastalarda yüksek oranda kardiyak ve serebrovasküler katastrofilere yol açabilmektedir. Yaşlıların atrofik derileri de yanık yaralarında ve donör bölgesinin iyileşmesinde problemlere yol açmaktadır. Bu hastaların deri bileşenleri ve değişimleri yaşın artışı ile birlikte geciktiği için yara iyileşmesi de gecikmektedir (3). Derinin fiziksel özelliklerinin değişimine bağlı tabakalarının incelmesi yara iyileşmesindeki bozukluklara ve derin yanıkların genişlemesine yol açabilir (10). Buna ilave olarak iyileşmenin tüm fazlarında azalma, epidermal dönüşümün azalması, deri eklerinin ve vaskülaritenin azalması, kollajen, matriks, fibroblast ve makrofaj seviyelerinin azalması görülmektedir (11). Bunlar spontan epitelizasyonu geciktirip özellikle ikinci derece yanık alanlarının derinleşmesine ve komorbid hastalıkların eklenmesiyle birlikte donör alanda iyileşme problemi yaşanmasına ve hatta mortaliteye yol açabilir. Bu nedenle verilerimize de dayanarak CIC skoru yüksek çıkan yani komorbid hastalıkların şiddeti yüksek olan geriatrik hastalarda yoğun bakım intiyacı doğabileceğini düşünüyoruz.

Yanığın şiddetini belirleyen diğer önemli bir faktör olan TVYA oranı genç erişkinlerde $\% 80$ olduğunda $\% 50$ mortaliteye neden olduğu, $60-70$ yaş arasında \%35 oranının aynı oranda mortaliteye neden olduğu kaydedilmiştir. Ayrıca 70 yaşın üzerindekilerde $\% 20$ TVYA oranı dahi $\% 50$ oranda mortaliteye neden olduğu gösterilmiştir $(9,12)$. Stassen ve ark. ortalama moratlite oranını $\% 45$ olduğunu ve 80 yaşından büyük hastalarda \%40 veya daha fazla oran TVYA'nın $\% 100$ mortaliteye yol açtığını belirtmiştir (13). Uygur ve ark. yaş ortalaması 75 olan 26 hastada TVYA oranı $\% 43$ iken mortalite oranının $\% 61,5$ olduğunu belirtmiş̧ir (2). Düzgün ve ark. ise yaş ortalaması 75 olan 54 hastada mortaliteyi etkileyen faktörleri incelediğinde sadece yanık alanının \%30'dan fazla olmasının bağımsız prognostik faktör olduğu sonucuna varmıştır (1). Çalışmamızda yaş ortalaması 74 olan 85 hastada mortalite oranını tüm hastalar için $\% 17,44$ ve yoğun bakım hastaları için \%39,47 olarak hesapladık. Yukarıdaki raporlardan farklı olarak TVYA oranlarını yüzdelerine göre grupladığımızda yoğun bakımda yatan hastaların yarısının \%20'nin üzerinde yanık alanına 
sahip olduğunu ve TVYA ile mortalite arasında anlamlı pozitif bir ilişki olduğunu kaydettik. Bu tip hastaların sıvı dengesi hassas olup hipotansif durumla birlikte renal hasar riski taşıdıkları için hemen yoğun bakıma alınarak sıvı resüsitasyonu başlatılması ve tedavi planlaması gerekmektedir (2). Literatürde yanık alanı \%5 TVYA'nı aşan yaşlı hastalarda resüsitasyon sıvısı kullanılması önerilmektedir. Artmış sıvı ihtiyacı pulmoner ödemi konjestif kalp yetmezliği ve pnömoni görülme riskini de artırmaktadır (2).

65 yaşın üzerinde kişilerde mobilizasyon kabiliyetinin azalmasına ve demansın artmasına bağlı olarak ev kazalarında yanıklara daha sık rastlanmaktadır (14). Düşük gelirli ülkelerde ev yangınlarına daha sık rastlanmakta ve yanık etiyolojisi arasında en çok bu yangınlara bağlı yanıklar görülmektedir (1). 15 mortal vakanın 11 'inde (\%73) görülen yanıklar alev yanıklarıdır ve bunlar tüm vakaların \%34'ünü oluşturmaktadır. Bu oran elektrik yanıklarına yakındır ve sıvı ile oluşan yanıklardan biraz fazladır (1). Uygur ve ark. yaşlı hastalarda yanığın oluş şeklini genellikle alev ile (\%76) gerçekleştiğini, bunu haşlanma yanıkları takip ettiğini (\%15) belirlemişlerdir. Yanık yarasının ciddiyeti ile inhalasyon yaralanmasının insidansı, azalmış reaksiyon zamanına bağlı olarak artmaktadır. Bu yaş grubunda görme, duyma fonksiyonlarını azalması ile reaksiyon zamanında düşüş meydana gelmekte ve bireyler zaman zaman muhakeme yeteneğini kaybetmektedir. Bu da çoğu zaman kazalarda ve yaralanmalarda temel etkendir (2). II han ve ark. genç hastaların da dahil olduğu 110 yanık vakası ile yaptıkları çalışmada yanık etiyolojilerinden alev, elektrik ve haşlanma yanığı sıkıklarını sırasıyla $\% 53,7, \% 30,0$ ve $\% 11,8$ olarak kaydetmiştir (15). Çalışmamızda serviste yatan hastaların çoğunda $(\% 54,2)$ sıvı yanığı, az sayıda hastada kimyasal, temas yanıkları elektrik yanığı görüldü. Literatüre benzer şekilde yoğun bakımda yatan hastalarımızın yarısında (\%50) alev yanığı, azında $(\% 7,9)$ kimyasal yanık görüldü fakat hiçbirinde temas veya elektriğe bağlı yanık görülmedi. Yanık etiyolojileri açısından gruplar arasında anlamlı fark yoktu fakat alev ile oluşan yanıkların oranı ile mortalite oranları arasında pozitif bir ilişki saptandı. Bu da alev ile oluşan yanıklarda ilk değerlendirmenin ardından yoğun bakım intimalinin göz ardı edilmemesi gerektiğini göstermiştir. Ayrıca hastaların kardiyovasküler sistemlerinin detaylı incelenmesi, risk faktörlerinin belirlenmesi gerekebilir ve sonrasında hastalar monitorize edilerek takip edilmelidir.

Yanığın tedavisini etkileyen faktörlerden bir diğer yanık bölgesidir. Emami ve ark. 55 yaş üzeri 187 hasta ile yaptıkları çalışmada mortalitenin yanık bölgesi ile ve yanı derinliği ile ilişkili olmadığını söylemişlerdir (16). Ancak anatomik bölge olarak sadece el veya el ve boyun yanıklarını seçmişleridir. Ayrıca literatürde genel olarak kabul edilen yaşlı hasta gruplarının minimum yaşları 65 iken Emami ve ark. 55 yaş üzeri hastaları tercih etmişlerdir (16). Çalışma- mızda 65 yaş üzeri serviste takip edilen hastaların anatomik yanık bölgelerine göre dağılımı incelendiğinde vakaların çoğunda $(\% 31,25)$ ayakta yanık görülürken en az $(\% 2,08)$ başta veya yüzde yanık görülmüştür. Yoğun bakımda yatan hastaların çoğunda $(\% 60,53)$ ise alt ekstiremitede en az $(\% 31,58)$ ayakta yanık oluşmuştur. İki grup arasında baş/yüz, üst ekstiremite, gövde ve alt ekstiremite yanıklarının insidansları açısından anlamlı farklara rastlanmıştır. Ayrıca el, gövde, alt ekstiremite ve ayakta oluşan yanıkların mortaliteyle pozitif bir ilişkisi olduğu kaydedilmiştir. Bu da yaşlılarda meydana gelen yanıklarda lokalizasyona göre tedavi planının ve yoğun bakım intiyacının değişebileceğini akla getirmektedir.

Yaşı hastalarda cerrahi müdahalelerin ve debritman veya eskaratomi gibi ek müdahalelerin ve greft uygulamalarının zamanlaması önemlidir (10). Uygur ve ark. ikinci derece yanık olgularında operasyon için 3 hafta beklenilmesi gerektiği, epitelizasyonun bu sürede gerçekleşmediği olgularda operasyon kararı aldıklarını belirtmiştir (2). Ancak bunun standart olarak uygulanmaması gerektiğini düşünüyoruz. Üçüncü derece yanıklarda genel durumu stabil olduğu, inhalasyon yaralanmasının olmadığı olgularda "erken yanık debridmanı" (eksizyon) ve greftlemeyi tercih ettiklerini belirtmiştir (2). Biz de servisimizde hastanın genel durumuna bağlı olarak eksizyon ve greftlemeyi uygulamaktayız. Yapılan debritman veya eskaratomi sayısı 10'dan fazla uygulanan hasta sayısı yoğun bakımda yatan hastalar arasında anlamlı derecede fazla bulunmuştur. Cerrahi müdahale uygulama sayısı ile mortalite arasında anlamlı pozitif bir ilişki saptanmış fakat greft uygulaması ile arasında bir korelasyona rastlanmamıştır. Bu da opere edilen ve yoğun bakımda tedavi edilen yaşlı hastalarda cerrahi gereksinimIerinin mortalite açısından da değerlendirilmesi gerektiğini göstermektedir.

Literatürde yanık hastaları arasında mortalite oranları çaIışmalar arasında farklılık göstermektedir. Örneğin İlhan ve ark. genç ve yaşlı hastaların bir arada bulunduğu popülasyonda kaba mortalite oranını \%10,9 olarak kaydetmiş̧ir (15). Soltani ve ark. \%51-64 arasında (17), Zarei ve ark. ise $\% 33,4$ gibi yüksek mortalite oranları (18) bildirmişlerdir. Demirel ve ark. ülkemizde yaptıkları çalışmada mortalite oranını \%30,4 vermiştir (19). Yorgancı ve ark. yaş aralığı temel alınarak 45 ile 60 arasında \%48, 61 ile 69 arasında $\% 45$ ve 70 yaş üzerinde ise $\% 56$ gibi mortalite oranları bildirmiştir (20). Uygur ve ark. ise yaşları 66- 93 arasında değişen 26 hastada mortalite oranını \%61,5 olarak bildirmişlerdir (2). Bizim yaşlı hasta grubumuzda bu oran \%17,44 idi ve bu hastaların hepsi yoğun bakımda yatan hastalardandı. Bu farklııkların nedeni olarak hastaların yaş ortalamaları, hasta kabulünde TVYA oranı ve yanık derinliği, yanık etiyolojilerinin ve bölgelerinin değişkenliği ve komorbid hastalıkların varlığı sayılabilir.

Sonuç olarak Türk popülasyonunda geriatrik hastalarda yanığa bağlı mortalite ve morbidite genç hastalara kıyasla 
yüksek olması, bu özel hasta grubunun tıbbi ihtiyaçlarının fazla olması anlamına gelir. Yanık hastaları arasında mortalitesi en yüksek oranlarda bulunan bu yaş grubu gerek eşlik eden hastalıklar gerekse yaşlanmanın vücudun tüm sistemleri üzerine olan olumsuz etkisi nedeniyle hem tedavi hem de takibinde multidisipliner yaklaşım ile mortalite ve morbiditenin azalabileceğini umuyoruz. Ayrıca çoğu yanık vakasının ev kazalarında sıvı dökülmesi veya alev ile yaralanmalara bağıı olması nedeniyle mortalite oranları yaşlı bireylerin yaşadıkları ortamlarda önlem alınmasıyla azalabilir.

\section{Kaynaklar}

1. Düzgün AP, Özmen MM, Senel E, Coşkun F. Factors influencing mortality in elderly burn patients. Geriatri 2003; 6 (2): 55-58.

2. Uygur $F$, Noyan $N$, Yüksel $F$, Çeliköz B. Yanık travmasında önemli bir grup: yaşlı hastalar 26 hastadaki klinik deneyimlerimiz. Türk Plastik Rekonstrüktif ve Estetik Cerrahi Dergisi 2010; 18 (2): 57-61.

3. Pruitt BA, Wolf SE, Mason AD. Epidemiological, demographic, and outcome characteristics of burn injury. In: Herndon DN, ed. Total Burn Care. Philadelphia: WB Saunders, 2012: 15-45.

4. Redlick F, Cooke A, Gomez M, Banfield J, Cartotto RC, Fish JS. A survey of risk factors for burns in the elderly and prevention strategies. Burn Care Rehabil 2002; 23(5):351-56.

5. Charlson ME, Pompei $P$, Ales KL, MacKenzie CR. A new method of classifying prognostic comorbidity in longitudinal studies: development and validation. J Chronic Dis 1987;40(5):373-83.

6. Beddhu S, Bruns FJ, Saul M, Seddon P, Zeidel ML. A simple comorbidity scale predicts clinical outcomes and costs in dialysis patients. Am J Med. 2000 ;108(8):609-13.

7. PorroLJ, Demling RH, Pereira CT, Herndon DN. Care of geriatric patients. In: Herndon DN, ed. Total Burn Care. Philadelphia: WB Saunders, 2012: 415-19.

8. Cutillas M, Sesay M, Perro G. Epidemiological of elderly patients burns in the South West of France Burns 1998;24 (2): 134-38.

9. Koupil J, Brychta $P$, Rihova $H$, Kincova S. Special features of burn injuries in elderly patients. Acta Chir Plast 2001; 43(2): 57-60.

10. Kirn D, Luce E. Early Exicision and grafting versus conservating management of burns in the elderly. Plast Recontr Surg 1998; 102(1):1013-17.

11. Kurban $R$, Bharvan $T$. Histologic changes in skin associated with aging. J Dermatol Surg Oncol 1990; 16(2): 908-14.

12. Laloe VV. Epidemiology and mortality of burns in a general hospital of Eastern Sir Burns 2002; 28 (8): 778-81.

13. Stassen NA, Lukan JK, Mizuguchi NN, Spain DA, Carillo EH, Polk $\mathrm{HC} \mathrm{Jr}$. Thermal injury in the elderly: when is comfort care the right choice? Am Surg 2001; 67(7): 704-08.

14. Wibbenmeyer LA, Amelon MJ, Morgan LJ, Robinson BK, Chang PX, Lewis $\mathrm{R}$, et al. Predicting Survival in an elderly burn patient population. Burns 2001; 27(6): 583-90.

15. İlhan E, Cengiz F, Demirkuran MA, Yılmaz S, Deneçli AG. İzmir Bozyaka Eğitim ve Araştırma Hastanesi Yanık Ünitesi'nde 15 aylık deneyimimizin değerlendirilmesi. Ulusal Cerrahi Dergisi 2011; 27(3): 154-58.

16. Emami SA, Motevalian SA, Momeni M, Karimi H. The epidemiology of geriatric burns in Iran: A national burn registry-based study. Burns 2016 ;42(5):1128-32.

17. Soltani K, Zand R, Mirghasemi A. Epidemiology and mortality of burns in Tehran, Iran. Burns 1998;24(1):325-28.

18. Zarei M-R, Dianat S, Eslami V, Harirchi I, Boddouhi N, Zandieh A, et al. Factors associated with mortality in adult hospitalized burn patients in Tehran. Ulus Travma Acil Cerrahi Derg 2011;17(1):61.

19. Demirel $Y$, Çöl C, Özen M. Ankara Numune Eğitim ve Araştırma
Hastanesi Yanık Servisinde bir yılda izlenen hastaların değerlendirilmesi. Cumhuriyet Üniversitesi Tıp Fakültesi Dergisi. 2001;23(1):15-20.

20. Yorgancı K, Elker D, Kabay B, Kaynaroğlu V, Öner Z, Sayek I. Kırkbeş yaş üstü yanık hastalarında tedavi sonuçları. Türk Geriatri Dergisi. 2001; 4(2): 116-19. 